\title{
Anxiety and Facial Self-Contacts as Risk Factors for COVID-19 in Dental Practice.
}

\author{
María Carrillo-Díaz \\ King Juan Carlos University \\ Laura Lacomba-Trejo \\ University of Valencia \\ Antonio del Valle-Gonzalez \\ King Juan Carlos University \\ Martín Romero \\ King Juan Carlos University \\ María José Gonzalez-Olmos ( $\nabla$ mariajose.gonzalez@urjc.es ) \\ King Juan Carlos University
}

\section{Research Article}

Keywords: COVID-19, Touch, Dental fear, anxiety, high risk

Posted Date: December 15th, 2020

DOI: https://doi.org/10.21203/rs.3.rs-118716/v1

License: (c) (1) This work is licensed under a Creative Commons Attribution 4.0 International License. Read Full License

Version of Record: A version of this preprint was published at BMC Oral Health on April 20th, 2021. See the published version at https://doi.org/10.1186/s12903-021-01564-6. 
Title page: Anxiety and facial self-contacts as risk factors for Covid-19 in dental practice.

\section{Authors}

María Carrillo-Diaz ${ }^{1}$ Phd, Dds: maria.carrillo@urjc.es

Laura Lacomba-Trejo ${ }^{2}$ Mg, Psych: laura.lacomba@uv.es

Antonio del Valle-González ${ }^{1}$ Phd, Med: Antonio.delvalle@urjc.es

Martín Romero-Maroto ${ }^{1}$ Phd, Med: martin.romero@urjc.es

María José González-Olmo ${ }^{1}$ Phd, Dds: mariajose.gonzalez@urjc.es

1 Dentistry Department in Rey Juan Carlos University, Avda de Atenas s/n 28922, Alcorcón, Madrid, Spain.

2 Faculty of Psychology, Department of Personality, Assessment and Psychological Treatments, University of Valencia, Av. Blasco Ibáñez, 21, 46010, Valencia, Spain.

Corresponding author:

María José González-Olmo, Orthodontic and Pediatric dentistry Department, Universidad Rey Juan Carlos, Avda de Atenas s/n 28922 Alcorcón, Madrid (Spain). E-mail: mariajose.gonzalez@urjc.es

Telephone number: 685907014 
Title: Anxiety and facial self-contacts as risk factors for Covid-19 in dental practice.

\begin{abstract}
Background: This study makes innovative contributions regarding the association of facial self-contact frequency and duration in dental clinic patients with psychosocial factors such as dental fear, fear of COVID-19 and trait anxiety, because such self-contact could have an impact on the transmission of SARS-CoV-2.
\end{abstract}

Results: Statistically significant associations were found between the number and duration of facial self-contacts with trait anxiety and dental fear. Women showed more frequent self-contact of the face in general and considering dental anxiety, we observe that the amount of self-contact for women remained. However, in men as dental fear increases, so do facial self-contacts. Trait anxiety is a mediating variable in the relationship between dental anxiety and the number of facial self-contacts.

Conclusions: There is a positive association between the number of facial self-contacts and trait anxiety and dental anxiety. However, there is no association between selfcontacts and fear of COVID-19. Women make a greater number of facial self-contacts, more trait anxiety and more dental anxiety. The relationship between dental anxiety and self-contacts was moderated by gender and the relationship between dental anxiety and self-contacts is mediated by trait anxiety.

Keywords: COVID-19, Touch, Dental fear, anxiety, high risk

\title{
INTRODUCTION
}

Starting in early 2020, a new human coronavirus, SARS-CoV-2, became a global health problem, COVID-19, that causes severe respiratory tract infections in humans, leading to a large number of deaths [1]. The total magnitude of the global economic, political, and social consequences is not yet known. We also do not know its potential impact on health 
systems and/ or on dental services. In fact, we do not have universal guidelines for providing dental care during the pandemic nor after it. Without an official protocol, the provision of dental care was either completely halted or significantly reduced to only urgent dental care, which may harm a patient's oral health.

One main reason for stopping dental care was that an asymptomatic person may be a potential source of transmission, so we must treat all patients in dental clinics as possible SARS-CoV-2 carriers [2]. In addition, COVID-19 can be transmitted from dry contaminated surfaces, including self-inoculation via the mucous membranes of the nose, eyes or mouth [3]. Although literature on the autoinoculation mechanisms of common respiratory infections is limited, contaminated hands in this context can spread respiratory infections [4].

No specific therapies are available for SARS-CoV-2, so early containment and prevention of further spread are crucial in stopping the outbreak [5], therefore, preventing the virus's spread in public and health-care settings is important [2].

Psychosocial consequences of the COVID-19 pandemic include: fear of selfcontamination or of spreading the contagion to people close to them; stress from continuous economic, political and social changes; emotional problems resulting from isolation; and distress from the possibility or reality of losing a loved one [6]. All these circumstances exacerbate add to patients' premorbid profiles (socioeconomic difficulties, personality, physical and mental health problems, etc.) [7]. If we consider differences associated with gender, studies consistently show that females have more anxiety levels [8]. Pre-pandemic factors also should be considered; the literature has shown that patients commonly experience stress when undergoing dental treatment [9]. In addition, patients with greater neuroticism, such as high trait anxiety or other anxiety disorders, are more likely to fear dental care $[10,11]$. These emotions are associated with avoidance of dental care, which can negatively impact the course, treatment, and outcome of dental pathologies [12].

According to Lang's (1968) theory of the three response systems, anxiety manifests via a triple-response system [13] that includes cognitive, behavioural, and physiological aspects [14]. In this sense, the varied psychophysiological responses to acute stress may include: tremors, tachycardia, sweating, and increased movements, such as touching the face and/or manipulating objects [15]. These movements occur unconsciously and can 
help regulate emotions [16]. It has been observed that people with anxiety or dental anxiety present a higher heart rate, higher heart rate variability and lower skin conductivity [17], as well as a greater amount of movement [14], but the association of these factors with facial self-contact has not been studied. This aspect is especially interesting because if people can touch their faces approximately 30 times an hour in situations that do not elicit anxiety [18], the number of facial self-contacts may increase in stressful situations [16] and increased facial self-contact may help transmit and spread the SARS-CoV-2 [19].

Therefore, the aim of the present research was to analyse the relationship between dental fear, trait anxiety, fear of COVID-19 and duration and frequency of facial self-contact; confirm gender differences in trait anxiety, dental anxiety and fear of COVID-19; and assess gender differences in facial self-contact related to dental anxiety, as well as to determine if dental anxiety is a mediating factor between trait anxiety and frequency of facial self-contact.

\section{METHOD}

\section{Design type}

This transversal design research was carried out in Spain from March 18 to May 15, 2020, during the initial stage of the pandemic. Since the World Health Organization officially declared the global pandemic, Madrid has established itself as one of the focuses of COVID-19 in Europe. By May 15, in Spain, there were 230,871 infected cases recorded, 123,182 hospitalized patients and 27,117 deaths.

\section{Data collection}

The participants comprised 124 adult patients (over 18 years old) who attended four dental clinics in Madrid. At the time of data collection in Spain, dental activity was limited exclusively to emergency treatment by the Spanish Order SND/310/2020 issued on March 31. All the patients were regular patients of the clinics, who had phoned for an appointment to resolve a dental emergency. The study's objectives and nature were explained beforehand by telephone, and patients who agreed to participate in the study were enrolled. At this point, patients were informed that this appointment would be exclusively for diagnosis and another appointment for treatment would be scheduled. The 
dental sector in Spain is not covered by the State, except for some special conditions for children. The adult population attends private clinics for dental care.

Patients were asked to come to the dental clinic at the agreed-upon time (to avoid unnecessary waiting) unaccompanied and with mask. One patient was scheduled per hour to avoid person-to-person contact. Upon arriving at the clinic, patients were asked to rub their hands with a hydroalcoholic gel and to put on shoe covers, as established by the protocol for preventing COVID-19 transmission in Spain [20].

The patients were informed that their behaviour in the waiting room would be observed for a study. To blind them to the study, they were not informed about which behaviours were under observation to minimize the potential for behavioural changes due to being observed [21]. After entering the waiting room, participants signed the informed consent form before their movements were monitored and were instructed to sit in a chair. The movement monitoring time was the minimum time for preparation and disinfection of the dental chair area. We considered that from an ethical point of view and with the risk situation we were in. The average time in the waiting room was $10.2( \pm 3.8)$ minutes. The amount and duration of facial self-contact were independently monitored, as were the number and duration of contacts made to the mask and eyes.

After this recording, participants filled out self-administered instruments using Google Forms to avoid further contact. The questionnaire's link was sent via e-mail or WhatsApp to their mobile device, and they completed it before entering the dental office.

This research is supported by the King Juan Carlos University Ethics and Research Committee.

Instruments:

An ad hoc questionnaire was developed to evaluate socio-demographic variables of age, gender, and educational level.

The Microsoft Kinect was used to evaluate the detection and counting of movement patterns [22].

Anxiety symptomatology was evaluated as a trait using the trait anxiety subscale of the State-Trait Anxiety Inventory (STAI) [23]. 
Fear of COVID-19 was assessed using the COVID-19 Fear Questionnaire (FCV-19S), recently developed by Ahorsu and colleagues (March, 2020) [24].

The short version of the Dental Anxiety Inventory (DAI) [25] was used to assess the physical reactions, thoughts, and behavioural aspects of people's dental fear.

The description of the instruments is attached in the online Appendix.

\section{Statistical Analysis}

The study presents a cross-sectional descriptive study considering the variables described in the previous section. A statistical analysis was performed using SPSS version 26 (SPSS Inc., Chicago, IL, USA). The data analysis included descriptive statistics, the Kolmogorov-Smirnov test to evaluate the assumption of normality, which was confirmed. As well as, analysis of differences in means with t-test or ANOVAs, with post hoc tests and effect sizes calculations. For t of independent samples, a Cohen's $d$ was performed. Low effect sizes was considered $d \approx 0.2$, medium was $\approx 0.5$, and high was $\approx 0.8$ [26]. The relationships between variables were analyzed using Pearson's correlations. Significance levels were established at 0.05 .

Subsequently, a PROCESS module (version 3.3) by Hayes [27] for SPSS, was used to perform moderation models (model 1) to observe if sex moderates the relationship between dental anxiety and self-contacts and multiple simple mediation analyses (model 4) to observe whether trait anxiety is a mediating factor between dental anxiety and facial self-contacts.

\section{RESULTS}

The sample comprised 64 (51.6\%) men and 60 (48.4\%) women, with an age range of 24 to 62 years (41.2 \pm 11.4$)$. In terms of educational levels for the total sample, $55.6 \%$ had completed primary school, $22.6 \%$ had completed secondary school, and $21.8 \%$ had obtained a university degree.

Facial self-contact patterns were observed in $93.5 \%$ of the registered patients, with an average of $7.2(\mathrm{SD}=4.8)$ contacts, $4.1(\mathrm{SD}=2.9)$ for mask contacts and $3.04(\mathrm{SD}=1.9)$ for eye contacts. The average time in the waiting room was $10.2( \pm 3.8)$ minutes, with 0.76 $(\mathrm{SD}=0.67)$ facial self-contacts per minute, and $0.44(\mathrm{SD}=0.40)$ mask contacts per minute and $0.32(\mathrm{SD}=0.28)$ eye contacts per minute were registered. The average duration of facial contact was $0.6(\mathrm{SD}=0.2)$ contacts per minute, with $0.3(\mathrm{SD}=0.1)$ 
contacts per minute for the mask and $0.2(\mathrm{SD}=0.1)$ contacts per minute for the eyes. Values for trait anxiety $(M=22.6 ; S D=18.1)$, fear of COVID-19 $(M=17.4 ; S D=9.1)$ and dental anxiety $(\mathrm{M}=19.1 ; \mathrm{SD}=8.3)$ were moderate.

Table 1 reveals statistically significant associations between the number and duration of facial, mask and eye self-contact with trait anxiety and dental fear. Similarly, trait anxiety was associated with higher dental fear in general and with fear of COVID-19. Associations were generally moderate or high, but fear of COVID-19, showed generally weak linear associations. Dental fear is associated with the frequency but not the duration of contact.

We examined mean differences in sociodemographic factors (age, gender and educational level) regarding the target variables. Statistically significant differences were only found concerning participants' gender. As shown in Table 2, women showed more frequent selfcontact of the face in general $(\mathrm{p}<0.05)$, and of their eyes and mask in particular $(\mathrm{p}<$ $0.05)$. They had longer facial and eye contact $(\mathrm{p}<0.05)$, greater trait anxiety $(\mathrm{p}<0.01)$ and greater dental fear $(\mathrm{p}<0.01)$. Moderate/large effect sizes were observed in all comparisons.

The moderating role of gender was evaluated (Table 3 ). The interaction between gender and dental anxiety significantly increased the coefficient of determination $(F=3.93 ; \Delta R 2$ $=0.09 ; \mathrm{p} \leq 0.05)$. With regard to the conditional effects, the impact of gender on selfcontact was significant for men $(t=2.53 ; p \leq 0.05 ; 95 \% \mathrm{CI}=[0.05,0.39])$, but not for women $(\mathrm{t}=-0.14 ; \mathrm{p}>0.05 ; 95 \% \mathrm{CI}=[-0.15,0.13])$. Thus, we observed that the amount of self-contact for women remained stable. However, in the case of men, as dental fear increases, so does facial self-contact.

We explored the possibility that dental anxiety could be a moderating factor between trait anxiety and the frequency of facial self-contact. With respect to the moderation analysis, no significant interaction effects were observed between trait anxiety and facial self-contact, considering dental anxiety as a moderator $(\mathrm{t}=2.39 ; \mathrm{p} \leq 0.05 ; 95 \%$ $\mathrm{CI}=[0,0.01])$. Finally, to determine the trait anxiety's mediating capacity between dental anxiety and regression data, dental anxiety is a good predictor of trait anxiety $(\beta=0.83, p<0.01)$ and of the number of facial self-contacts $(\beta=0.14 ; p<0.01)$. In addition, trait anxiety also directly associated with the number of facial self-contacts $(\beta=0.09$, $\mathrm{p}<0.01)$. Indirect relationships, which result from including dental anxiety and trait 
anxiety in a multiple regression equation (with the number of self-contacts as the criterion), showed trait anxiety as a statistically significant mediator between dental anxiety and the number of facial self- contacts $(\beta=0.12, p<0.01)$ (Table 4$)$.

Therefore, more dental anxiety increases the number of facial self-contacts, but this is because greater dental anxiety results from greater trait anxiety, which therefore yields more self-contacts (Figure 1)

\section{DISCUSSION}

This study makes innovative contributions regarding the association of facial self-contact frequency and duration in dental clinic patients with psychosocial factors such as dental fear, fear of COVID-19 and trait anxiety, because such self-contact could have an impact on the transmission of SARS-CoV-2.

Our data partially align with previous studies, such that trait anxiety and dental fear relate to a subject's amount of facial self-contact, but fear of COVID-19 does not seem to relate. However, COVID-19-related fear is very specific and related to (possible or perceived risk of) contamination. This perception would be associated with a hypervigilance against threats (i.e., "germs") and hygienic behaviours such as avoiding facial self-contact [28]. Previous research has pointed out the association between anxiety and frequency of facial self-contact [16, 29]. However, no study has analysed the relationship between fear of COVID-19 and facial self-contact, an issue we address in our research to make an interesting contribution to this current scientific problem.

Our study is unique, too, in its investigation of the gender variable moderation in the relationship between dental anxiety and facial self-contact, as well as the trait anxiety variable mediation between dental fear and facial self-contact. We also aimed to understand how facial self-contact frequency might be associated with dental anxiety and fear of COVID-19.

Our data show that dental anxiety and trait anxiety are higher in women, as others have previously reported $[30,31]$. However, we also show that the frequency of self-contact is higher in women, but according to the moderation analyses, we found innovative results, because we observed that the number of self-contacts increased in men as dental anxiety increased, but this relationship did not occur in the case of women. As the literature consistently points out, women tend to show more anxiety in general [30, 31], and in this 
case specifically, we observed that self-contact in women, despite being older, remained stable regardless of the dental anxiety they presented.

Our participants all wore masks; however, the frequency of self-contact was similar to that reported without masks [18]. On the other hand, trait anxiety was a mediating factor for the number of facial self-contacts in the waiting room when subjects faced dental fear. This implies that, even with similar levels of dental fear, people with less trait anxiety will make fewer facial self-contacts to the eyes and mask and therefore could be more protected from infection. These data provide important new knowledge because numerous studies have linked touching a mask by hand to an increased risk of infection and cross-contamination $[32,33]$.

Despite our study's contributions, the results should be interpreted with caution. First, the study sample was small because the participants were recruited during Spain's period of confinement, and were patients who attended the clinics due to an emergency. In addition, we used convenience sampling, so subsequent studies are necessary to continue investigating the reality of the patients who attend dental clinics via probability sampling. Future studies should monitor the time each patient spends in the waiting room, the number of times patients wash their hands, and touch surfaces, as these may be associated with a greater likelihood of infection. Furthermore, thoughts associated with anxiety could be evaluated qualitatively, and other behaviours or physiological responses associated with anxiety, such as heart rate or skin conductance, could be evaluated quantitatively [34].

In addition, using questionnaires can lead to social desirability bias, but objective evaluation methodologies significantly reduce the impact of this bias. In our research, both measures were consistently associated. Importantly, the above results do not indicate causal relationships between the variables of interest. The present investigation's design only allows us to conclude that significant relationships exist between the variables. Thus, more ample future studies are required to clarify the obtained results and to evaluate the temporary reliability of our data.

Two groups of applications for dentistry are obtained from our results, depending on whether the practical implications are considered via the prevention of COVID-19 or via psychological intervention. 
From the point of view of COVID-19 prevention:

The WHO recommends "ensuring that environmental cleaning, and disinfection procedures are followed consistently and correctly". SARS-CoV-2 can persist on inanimate surfaces for a long time, but can be effectively inactivated via surface disinfection in 1 minute using $62-71 \%$ ethanol, $0.5 \%$ hydrogen peroxide, or $0.1 \%$ sodium hypochlorite [5]. Every time a patient leaves the waiting room, his chair, and environment must be disinfected before another patient takes that place to avoid cross-contamination. From the point of view of psychological intervention:

Based on the results obtained, we propose the inclusion of psychology professionals in the circuit of evaluation and intervention of patients who come to dental clinics. A psychological evaluation prior to the dentistry consultation could help to detect the patients who need a previous intervention. In this way, health psychologists could attend to patients who require this whit psychoeducation, relaxation techniques, rationalemotive therapy or the use of virtual reality [35, 36], so that when they arrive at the consultation, their level of discomfort is lower, and therefore facial self-contact will be reduced. These techniques, among others, could be applied in an online group format where patients could increase their level of social support, but the chances of contagion would be reduced. Other procedures could include caring for the work environment, such as using music therapy to establish a calming atmosphere in the waiting room and treatment rooms [37].

Future research should evaluate the psychological and medical aspects, considering an integral and multidisciplinary approach to health from a biopsychosocial point of view.

\section{CONCLUSIONS:}

- There is a positive association between the number of facial self-contacts and trait anxiety and dental anxiety. However, there is no association between self-contacts and fear of COVID-19.

- Women exhibit a greater amount of facial self-contact and experience more trait anxiety and dental anxiety. These gender differences in self-contact do not occur with respect to fear of COVID-19. 
- The relationship between dental anxiety and self-contact was moderated by gender in the case of men. In men, the greater the dental anxiety, the greater the amount of facial self-contact.

- The relationship between dental anxiety and self-contacts is mediated by trait anxiety.

\section{Declarations:}

-Ethics approval and consent to participate:

Ethical approval for this study was obtained from the Ethics Commission for Research at the King Juan Carlos University, Madrid. The informed consent procedure was approved by the Research Ethics Committee. Before starting the questionnaire, the research purpose of the collected information and the confidential guarantee policy were disclosed and informed consents were obtained from all participants. All responses were voluntary and anonymous.

-Consent for publication:

Not applicable.

-Availability of data and materials:

The datasets generated during and analyzed during the current study are not publicly available due to national data protection law but are available from the corresponding author on reasonable request

-Competing interests:

I declare that the authors have no competing interests as defined by $\mathrm{BMC}$, or other interests that might be perceived to influence the results and/or discussion reported in this paper.

-Funding:

I declare that the authors have not received any type of funding for this study

-Authors' contributions

MCD, LLT and MGO designed the study. MCD, AVG and MGO collected data. LLT and MGO analyzed and interpreted data. AVG, MR and MCD drafted the manuscript. 
MCD, MGO and MR supervised the research and revised the manuscript for important intellectual content. All authors read and approved the final manuscript.

-Acknowledgements:

The authors would like thank the families that participate in this study.

-Author details

1 Dentistry Department in Rey Juan Carlos University, Avda de Atenas s/n 28922, Alcorcón, Madrid, Spain.2 Faculty of Psychology, Department of Personality, Assessment and Psychological Treatments, University of Valencia, Av. Blasco Ibáñez, 21, 46010, Valencia, Spain.3 Dentistry Department in Rey Juan Carlos University, Avda de Atenas s/n 28922, Alcorcón, Madrid, Spain.4 Dentistry Department in Rey Juan Carlos University, Avda de Atenas s/n 28922, Alcorcón, Madrid, Spain.5 Dentistry Department in Rey Juan Carlos University, Avda de Atenas s/n 28922, Alcorcón, Madrid, Spain.

\section{REFERENCES}

1. Wu F, Zhao S, Yu B, Chen YM, Wang W, Song ZG. A new coronavirus associated with human respiratory disease in China. Nature. 2020;579:265-9. https://doi.org/10.1038/s41586-020-2008-3

2. Abduljalil JM, Abduljalil BM. Epidemiology, genome, and clinical features of the pandemic SARS-CoV-2: a recent view. New Microbes New Infec.t 2020;35:100672. https://doi.org/10.1016/j.nmni.2020.100672

3. Li JO, Lam DSC, Chen Y, Ting DSW. Novel Coronavirus disease 2019 (COVID19): The importance of recognising possible early ocular manifestation and using protective eyewear. $\mathrm{Br} \quad \mathrm{J}$ Ophthalmol. 2020;104:297-8. https://doi.org/10.1136/bjophthalmol-2020-315994

4. Macias AE, de la Torre A, Moreno-Espinosa S, Leal PE, Bourlon MT, RuizPalacios, GM. Controlling the novel A (H1N1) influenza virus: don't touch your face. J Hosp Infect. 2009;73:280-1. https://doi.org/10.1016/j.jhin.2009.06.017

5. Kampf G, Todt D, Pfaender S, Steinmann E. Persistence of coronaviruses on inanimate surfaces and their inactivation with biocidal agents. J Hosp Infect. 2020;104:246-51. https://doi.org/10.1016/j.jhin.2020.01.022 
6. Mayland CR, Harding AJ, Preston N, Payne S. Supporting adults bereaved through COVID-19: a rapid review of the impact of previous pandemics on grief and bereavement. J Pain Symptom Manage. 2020; 60 (2): 33-9. https://doi.org/10.1016/j.jpainsymman.2020.05.012

7. Liu L, Wei Q, Alvarez X, Wang H, Du Y, Zhu H, et al. Epithelial cells lining salivary gland ducts are early target cells of severe acute respiratory syndrome coronavirus infection in the upper respiratory tracts of rhesus macaques. J Virol. 2011;85:4025-30. https://doi.org/10.1128/jvi.02292-10

8. Bekendam MT, Mommersteeg PMC, Kop WJ, Widdershoven, JW, Vermeltfoort, IAC. Anxiety and hemodynamic reactivity during cardiac stress testing: The role of gender and age in myocardial ischemia. J Nucl Cardiol. 2020;28. https://doi.org/10.1007/s12350-020-02079-3

9. Oosterink FM, de Jongh A, Hoogstraten J. Prevalence of dental fear and phobia relative to other fear and phobia subtypes. Eur J Oral Sci. 2009;117:135-643. https://doi.org/10.1111/j.1600-0722.2008.00602.x

10. Hägglin C, Hakeberg M, Hällström T, Berggren U, Larsson L, Waern M, et al. Dental anxiety in relation to mental health and personality factors. A longitudinal study of middle-aged and elderly women. Eur J Oral Sci. 2001;109:27-33. https://doi.org/10.1034/j.1600-0722.2001.00946.x

11. Lago-Méndez L, Diniz-Freitas M, Senra-Rivera C, Seoane-Pesqueira G, GándaraRey JM, Garcia-Garcia A. Dental anxiety before removal of a third molar and association with general trait anxiety. J Oral Maxillofac Surg. 2006;64:1404-8. https://doi.org/10.1016/j.joms.2006.05.030

12. Nicolas E, Bessadet M, Collado V, Carrasco P, Rogerleroi V, Hennequin M. Factors affecting dental fear in French children aged 5-12 years. Int J Paediatr Dent. 2010;20:366-73. https://doi.org/10.1111/j.1365-263x.2010.01054.x

13. Lang PJ, Melaned BG, Hart J. A psychophysiological analysis of fear modification using and automated desensitizacion procedure. J Abnorm Psychol. 1970;76:220-34. https://doi.org/10.1037/h0029875

14. Martínez-Monteagudo MC, Inglés CJ, Cano-Vindel A, García-Fernández JM. Current status of research on Lang's three-dimensional theory of anxiety. Ansiedad y Estrés. 2012;18:201-19. 
15. McEwen BS. Physiology and neurobiology of stress and adaptation: central role of the brain. Physiol Rev. 2007;87:873-904. https://doi.org/10.1152/physrev.00041.2006

16. Mueller SM, Martin S, Grunwald M. Self-touch: Contact durations and point of touch of spontaneous facial self-touches differ depending on cognitive and emotional load. PLoS One. 2019;14: e0213677. https://doi.org/10.1371/journal.pone.0213677

17. Roos A, Goetz T, Voracek M, Krannich M, Bieg M, Jarrell A, et al. Test Anxiety and Physiological Arousal: A Systematic Review and Meta-Analysis. Educ Psychol Rev. 2020;16.

18. Kwok YL, Gralton J, McLaws M. Face touching: a frequent habit that has implications for hand hygiene. Am J Infect Control. 2015;43:112-4. https://doi.org/10.1016/j.ajic.2014.10.015

19. Nicas M, Best D. A Study Quantifying the Hand-to-Face Contact Rate and Its Potential Application to Predicting Respiratory Tract Infection. J Occup Environ Hyg. 2008;5:347-52. https://doi.org/10.1080/15459620802003896

20. Coem. Protocolo de prevención sanitaria frente al Covid-19. Colegio de Odontólogos de Madrid (COEM);2020. https://www.coem.org.es/media/news/pdf/protocoloCovidPacientesCOEM.pdf

21. Last J M. A dictionary of epidemiology. New York: Oxford University Press; 2001

22. Giakoumis D, Drosou A, Cipresso P, Tzovaras D, Hassapis G, Gaggioli A, et al. Real-time monitoring of behavioural parameters related to psychological stress. Stud health technol inform. 2012;181:287-91.

23. Spielberger CD, Gorsuch RL, Lushene R, Vagg PR, Jacobs GA. Manual for the State-Trait Anxiety Inventory. Palo Alto, CA: Consulting Psychologists Press; 1983.

24. Ahorsu DK, Lin CY, Imani V, Saffari M, Griffiths MD, Pakpour AH. The Fear of COVID-19 Scale: Development and Initial Validation. Int J Ment Health Addict. 2020;27:1-9. https://doi.org/10.1007/s11469-020-00270-8

25. Aartman IH. Reliability and validity of the short version of the Dental Anxiety Inventory. Community Dent Oral Epidemiol. 1998;26:350-4. https://doi.org/10.1111/j.1600-0528.1998.tb01972.x 
26. Cohen J. Statistical Power Analysis for the Behavioral Sciences. New York: Lawrence Erlbaum Associates Publishers;1988.

27. Hayes AF. PROCESS: A versatile computational tool for observed variable mediation, moderation, and conditional process modeling (White paper);2012. Retrieved from http://www.afhayes.com/ public/process2012.pdf

28. Asmundson GJG, Taylor S. How health anxiety influences responses to viral outbreaks like COVID-19: What all decision-makers, health authorities, and health care professionals need to know. J Anxiety Disord. 2020;71:102211. https://doi.org/10.1016/j.janxdis.2020.102211

29. Freedman N, O'Hanlon J, Oltman P, Witkin HA. The imprint of psychological differentiation on kinetic behavior in varying communicative contexts. J Abnorm Psychol. 1972;79:239-58. https://doi.org/10.1037/h0033162

30. Kinner VL, Het S, Wolf OT. Emotion regulation: exploring the impact of stress and sex. Front Behav Neurosci. 2014;8:397. https://doi.org/10.3389/fnbeh.2014.00397

31. Zinke A, Hannig C, Berth H. Psychological distress and anxiety compared amongst dental patients- results of a cross-sectional study in 1549 adults. BMC Oral Health. 2019;19:27. https://doi.org/10.1186/s12903-019-0719-3

32. Casanova L, Alfano-Sobsey E, Rutala WA, Weber DJ, Sobsey M. Virus Transfer from Personal Protective Equipment to Healthcare Employees' Skin and Clothing. Emerg Infect Dis. 2008;14:1291-3. https://doi.org/10.3201/eid1408.080085

33. Phan LT, Maita D, Mortiz DC, Bleasdale SC, Jones RM. Environmental Contact and Self-contact Patterns of Healthcare Workers: Implications for Infection Prevention and Control. Clin Infect Dis. 2019;69:S178-84. https://doi.org/10.1093/cid/ciz558

34. Marin M, Hammoud MZ, Klumpp H, Simon NM, Milad MR. Multimodal Categorical and Dimensional Approaches to Understanding Threat Conditioning and Its Extinction in Individuals With Anxiety Disorders. JAMA Psychiatry. 2020;77:618. https://doi.org/10.1001/jamapsychiatry.2019.4833

35. Lahti S, Suominen A, Freeman R, Lähteenoja T, Humphris G. Virtual Reality Relaxation to Decrease Dental Anxiety: Immediate Effect Randomized Clinical Trial. JDR Clin Trans Res. 2020;5:312-8. https://doi.org/10.1177/2380084420901679 
36. Gordon D, Heimberg RG, Tellez M, Ismail AI. A critical review of approaches to the treatment of dental anxiety in adults. J Anxiety Disord. 2013;27:365-78.

37. Lakshmanan R, Packyanathan J, Jayashri P. Effect of music therapy on anxiety levels on patient undergoing dental extractions. J Family Med Prim Care. 2019;8:3854. https://doi.org/10.1016/j.janxdis.2013.04.002 


\section{Tables}

Table 1. Intercorrelations between variables studied (Trait anxiety, Dental fear, Fear of COVID-19, Frequency and duration of self-contact) $n=124$

\begin{tabular}{|c|c|c|c|c|c|c|c|c|}
\hline & 2 & 3 & 4 & 5 & 6 & 7 & 8 & 9 \\
\hline Anxiety- trait & $0.261 * *$ & $0.273 * *$ & $0.620 * *$ & $0.620 * *$ & $0.617 * *$ & $0.706 * *$ & $.692 * *$ & $0.674 * *$ \\
\hline Dental fear & & $0.410 * *$ & $0.194 *$ & $0.196^{*}$ & $0.200^{*}$ & 0.167 & 0.159 & 0.158 \\
\hline Fear of covid-19 & & & 0.114 & 0.098 & 0.128 & 0.111 & 0.090 & 0.129 \\
\hline $\begin{array}{l}\text { Face Contact } \\
\text { frequency }\end{array}$ & & & & \multicolumn{5}{|c|}{$0.993 * * 0.986 * * 0.923 * * 0.923 * * 0.881 * *$} \\
\hline $\begin{array}{l}\text { Mask Contact } \\
\text { frequency }\end{array}$ & & & & \multicolumn{5}{|c|}{$0.966 * * 0.918^{* *} 0.933 * * 0.850 * *$} \\
\hline $\begin{array}{l}\text { Eyes Contact } \\
\text { frequency }\end{array}$ & & & & \multicolumn{5}{|c|}{$0.909 * * 0.884 * * 0.905 * *$} \\
\hline $\begin{array}{l}\text { Duration of face } \\
\text { contact }\end{array}$ & & & & \multicolumn{4}{|r|}{$.986^{* *}$} & \multirow[b]{2}{*}{$.911^{* *}$} \\
\hline $\begin{array}{l}\text { Duration of mask } \\
\text { contact }\end{array}$ & & & & & & & & \\
\hline $\begin{array}{l}\text { Duration of eye } \\
\text { contact }\end{array}$ & & & & & & & & \\
\hline
\end{tabular}


Table 2. Differences in Gender for Trait Anxiety, Fear of COVID-19, Dental Fear, Frequency and Duration of Self-contact.

\begin{tabular}{|c|c|c|c|c|c|}
\hline & \multicolumn{3}{|c|}{ Sex } & \multirow[b]{2}{*}{$\mathrm{p}$} & \multirow[b]{2}{*}{$d$} \\
\hline & $\begin{array}{c}\text { Mean (SD) } \\
\text { Man } \\
n=64\end{array}$ & $\begin{array}{c}\text { Mean }(\mathrm{SD}) \\
\text { Woman } \\
\mathrm{n}=60\end{array}$ & $t$ & & \\
\hline Trait-Anxiety & $17,7(15,7)$ & $27,7(19,1)$ & 3.15 & $0.002 * *$ & 0.56 \\
\hline Dental-fear & $16(6.75)$ & $22.36(8.72)$ & 4.46 & $0.001 * *$ & 0.80 \\
\hline Fear of covid-19 & $16.3(8.8)$ & $18.5(9.2)$ & 1.38 & 0.171 & 0.24 \\
\hline $\begin{array}{l}\text { Face Contact } \\
\text { frequency }\end{array}$ & $6.2(4.2)$ & $8.2(5.2)$ & 2.28 & $0.024 *$ & 0.42 \\
\hline $\begin{array}{l}\text { Mask Contact } \\
\text { frequency }\end{array}$ & $3.6(2.6)$ & $4.8(3.1)$ & 2.25 & $0.026^{*}$ & 0.41 \\
\hline $\begin{array}{l}\text { Eyes Contact } \\
\text { frequency }\end{array}$ & $2.6(1.6)$ & $3.4(2.1)$ & 2.34 & $0.021^{*}$ & 0.42 \\
\hline $\begin{array}{l}\text { Duration of face } \\
\text { contact }\end{array}$ & $0.58(0.27)$ & $0.69(0.31)$ & 2.01 & $0.047 *$ & 0.37 \\
\hline $\begin{array}{l}\text { Duration of mask } \\
\text { contact }\end{array}$ & $0.33(0.1)$ & $0.39(0.1)$ & 1.97 & 0.051 & 0.33 \\
\hline Duration of eye contact & $0.25(0.1)$ & $0.29(0.1)$ & 2.00 & $0.048 *$ & 0.34 \\
\hline
\end{tabular}
$d$ de Cohen $=$ TE small $\approx 0.20 ;$ TE medium $\approx 0.50 ;$ TE large $\approx 0.80$. 
Table 3. Moderating effects of sex on the relationship between trait anxiety and selfcontacts.

\begin{tabular}{|c|c|c|c|c|c|c|}
\hline & Effect & $\mathrm{SE}$ & $t$ & $p$ & LLCI & ULCI \\
\hline \multicolumn{7}{|c|}{$\begin{array}{l}\text { Model } \\
R^{2}=.09 ; F=3.93 ; p \leq .05\end{array}$} \\
\hline Dental anxiety & 0.22 & 0.09 & 2.53 & .01 & .05 & .39 \\
\hline Sex & 5.68 & 2.24 & 2.53 & .01 & $1-23$ & 10.12 \\
\hline Dental anxiety $*$ Sex & -.23 & 0.12 & -2.06 & .04 & -.45 & -.01 \\
\hline \multicolumn{7}{|l|}{ Conditional effects } \\
\hline Men & .22 & .09 & 2.53 & .01 & .05 & .39 \\
\hline Woman & -.01 & .97 & -.14 & .89 & -.15 & .13 \\
\hline
\end{tabular}


Table 4. Mediation analysis

\begin{tabular}{|c|c|c|c|c|c|c|c|c|c|c|}
\hline IV & M & $\mathrm{DV}$ & $\mathrm{R}^{2}$ & $\mathrm{p}$ & $\begin{array}{l}\text { Efect } \\
\text { of IV } \\
\text { on M }\end{array}$ & $\begin{array}{l}\text { Effect } \\
\text { of } \mathrm{M} \\
\text { on DV }\end{array}$ & $\begin{array}{l}\text { Direct } \\
\text { effect }\end{array}$ & $\begin{array}{l}\text { Interdirect } \\
\text { effect }\end{array}$ & $\begin{array}{l}95 \% \text { CI } \\
\text { for } \\
\text { indirect } \\
\text { effects }\end{array}$ & Total effect \\
\hline $\begin{array}{l}\text { Dental } \\
\text { anxiety }\end{array}$ & $\begin{array}{l}\text { Trait- } \\
\text { anxiety }\end{array}$ & $\begin{array}{l}\text { Self- } \\
\text { Contacts }\end{array}$ & .21 & .001 & $.83 * *$ & $.09 *$ & $.14 * *$ & $.12 * *$ & .07 to .17 & $.21 * *$ \\
\hline
\end{tabular}

Note. Bootstrap samples $=10,000 . R^{2}=$ Coefficient of determination. LLCI= Lower level of the $95 \%$ confidence interval. ULCI= Upper level of the $95 \%$ confidence interval

\section{Figure}

\section{Figure 1. Mediation analysis model}

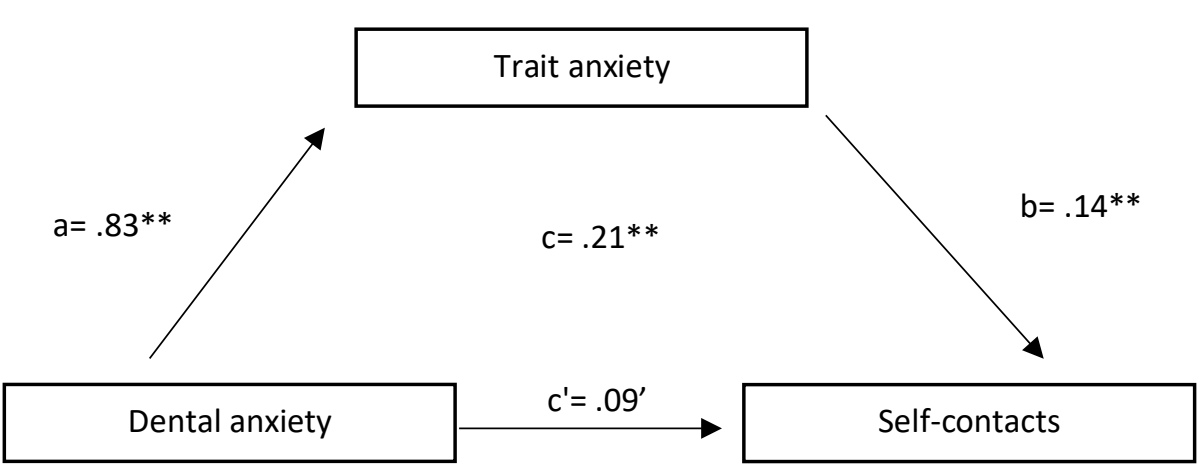


Figures

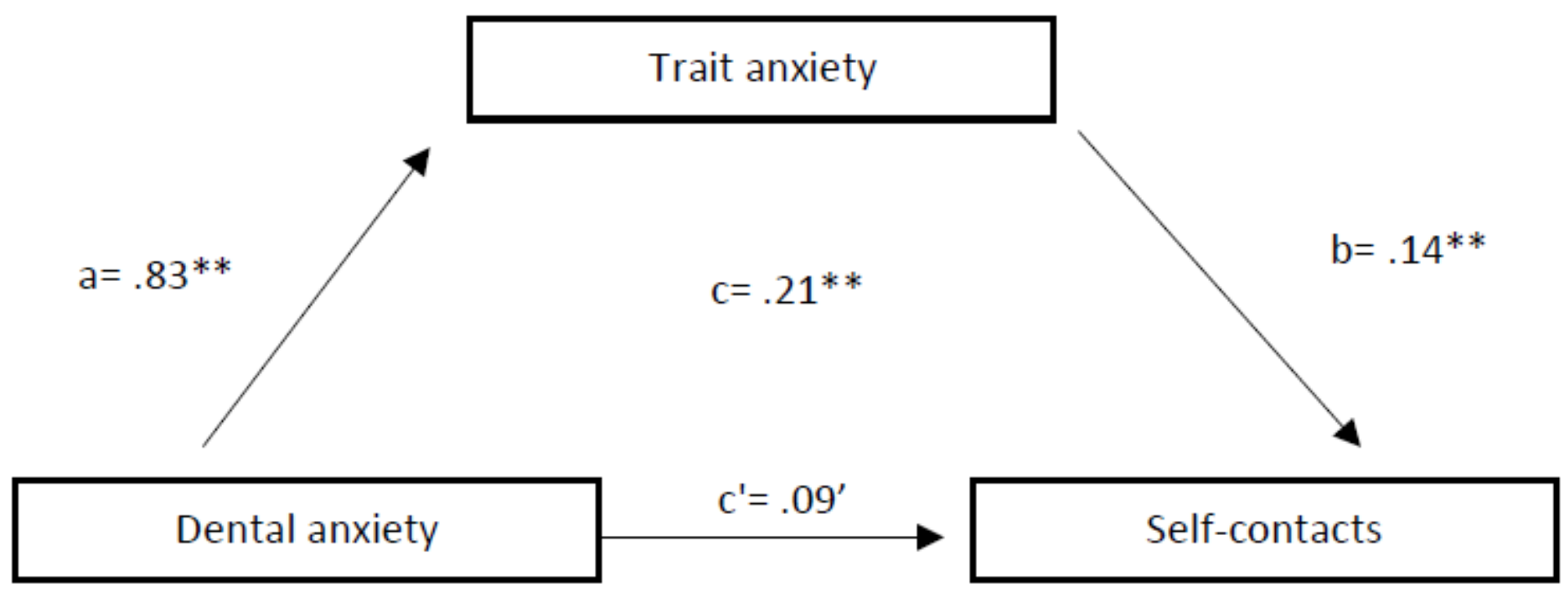

Figure 1

Mediation analysis model

\section{Supplementary Files}

This is a list of supplementary files associated with this preprint. Click to download.

- OnlineAppendix.pdf 